\title{
NOTA DE PESQUISA DE CAMPO
}

Trabalho de campo: uma ferramenta do geógrafo

\author{
Vicente Eudes Lemos Alves ${ }^{1}$
}

\begin{abstract}
"O instrumento mais importante que o geógrafo leva para o campo é o próprio cérebro. Lá, ele nāo se limita a olhar, o que fazem todos os que viajam: turistas, viajantes. o geógrafo precisa ver, que significa, olhar associado ao ato de refletir: Observar, enfim." (Orlando Valverde)
\end{abstract}

O trabalho de campo sempre foi uma ferramenta importante no estudo do geógrafo. Se resgatarmos um pouco da história do pensamento geográfico, atentaremos para o detalhe de que a prática da observação tornou-se um recurso imprescindivel para os geógrafos das mais distintas gerações e nacionalidades. Somente para lembrarmos, a geografia já nasce como ciência, valorizando esse espírito de buscar na observaçáo direta elementos para melhor compreensáo da paisagem. Humboldt, por exemplo, foi um desses geógrafos que primeiro utilizou essa ferramenta para explicar os fenômenos que se manifestavam na superficie da terra.

Aliás, a vasta obra de Humboldt baseou-se enormemente nas observaçōes por ele colhidas durante suas viagens aos vários lugares do planeta. ${ }^{2} \mathrm{O}$ mais interessante na obra desse autor é que, apesar de estar respaldada nas observaçōes, ela não se caracteriza como empirista, na medida em que Humboldt conseguia aliar o trabalho empirico ao abstrato. ${ }^{3} \mathrm{Um}$ outro elemento também importante em Humboldt é o fato de que ele considerava que a observaçāo da paisagem nāo devia ser um exercício frio, sem emoção, mas justamente o oposto, ou seja, a natureza ${ }^{4}$ devia

1 Estudante de Pós-graduação do Departamento de geografia . FFLCH/USP

2 O continente americano foi desses lugares que Humboldt conheceu. Permaneceu aqui durante cinco anos,principalmente na América do Sul e Central ( Venezuela. Colómbia, Peru e Cuba), onde produziu um material de grande utilidade não somente para a geografia, mas também para a Botănica, a Geologia, a Antropologia etc.

3 Moraes, A. C. R. Contribuiçáo para uma História Crítica do Pensamento Geográfico, p.43.

4 Em sua obra, Humboldt trabalha essencialmente com os elementos da natureza; o Homem é apenas mais um desses elementos. ser observada com os sentimentos, isto é, contemplada da maneira mais prazerosa possível, e para que isso ocorresse era preciso que o observador deixasse fluir toda a sua sensibilidade.

De acordo com suas próprias palavras:

"A natureza é o reino da liberdade, e para pintar vivamente as concepçōes e os prazeres que sua contemplação profunda espontaneamente engendra seria preciso dar ao pensamento uma expressão livre e nobre em harmonia com a grandeza e majestade da criação. "s

A herança deixada por Humboldt no que diz respeito à prática do trabalho de campo, no meu entender, constitui em um ensinamento importante para nós geógrafos, sobretudo para aqueles que adotam tal procedimento como um recurso a mais para o desvendamento da paisagem. Nesse sentido, considero que o trabalho de campo pode indicar caminhos que possibilitem obter novas interpretaçōes sobre a realidade estudada. Contudo, é importante estarmos atentos para o fato de que o ato de observar, para o geógrafo, não deve ocorrer nem sem emoçāo e muito menos sem o compromisso com a realidade que se investiga; é preciso, ao mesmo tempo, colocar em prática o exercicio de observar, aliado ao de sentir e refletir.

\section{UMA EXPERIÊNCIA DE TRABALHO DE CAMPO}

Algumas de minhas experiências com trabalho de campo demonstraram a necessidade de levar

5 Humboldt, A. Cosmos, V. 1, pg. 40 
em conta algumas das questões levantadas acima. Dessa forma, tentaremos neste artigo mostrar, a partir de uma das minhas experiências de campo, o quanto é necessário o exercício de observar aliado ao de refletir quando se faz uma investigação de um determinado tipo de paisagem.

Ingressamos no programa de pós graduação do Departamento de Geografia FFLCH/USP, em 1995, ao qual apresentamos como proposta estudar o processo de modernização do espaço agrário do Sul do Piauí, região de cerrados que recentemente vem se transformando em uma área de interesse do grande capital do setor agropecuário.

A intenção de estudar aquela área nasceu após uma curta visita ao local e algumas leituras que realizei sobre aquele fenômeno, principalmente nos veiculos da grande imprensa piauiense e também do Sudeste do país, nos quais frequentemente a interpretação apresentada sobre aquele processo era a de que estava ocorrendo, com a entrada do grande capital, uma 'revoluçāo' na regiāo, visto que a mesma possuía uma população predominantemente camponesa cuja base económica sustentava-se na agricultura de subsistência. Esta representava portanto, a face atrasada nesse novo contexto em que vivia o país, e no qual o Piauí começava a se inserir. Passava-se, então, que o moderno chegava para superar o atraso. ${ }^{6}$

Na primeira etapa do curso dedicamo-nos às leituras; dentre outras, àquelas que abordavam o processo de modernização do espaço agricola brasileiro, particularmente aquele que se deu nas regiōes de expansão das fronteiras agricolas do Centro-Oeste e mais recentemente do Nordeste (incluindo aqui também o Piaui, onde os grandes projetos agropecuários começaram a se instalar, principalmente nos cerrados do Sul do Estado, na década de 80). Após um volume considerável de leituras, percebemos que as mesmas nảo davam conta de explicar a realidade do Sul do Piaui, e que, portanto, precisariamos solucionar, "in loco", algumas de nossas questões. Preparamos, entāo, um trabalho de campo sistematizado, a ser desenvolvido junto à área pesquisada, e que executamos no mês de janeiro de 1997.

No nosso primeiro contato com a regiāo, percebemos que, no nivel da aparência, a modernização apresentava seus resultados a partir das planta-

6 Uma reportagem da revista ISTO É sobre a modenizaçāo da regiāo trazia o seguinte título: "O Piaui que dá certo". ISTO É. 3 de agosto de 1994, no 1296 , pg. 47. ções (soja, milho, arroz) em grandes propriedades que se tornavam por sua vez visiveis a todos que passavam pela estrada; também nas cidades apareciam alguns registros que nos indicavam que estavam ocorrendo transformaçōes recentes naquele espaço. Detectamos, dentre outras coisas, que havia ali uma convivência de duas culturas distintas e que se manifestavam, por exemplo, na arquitetura das residências - algumas com características da cultura local e outras construidas no estilo da cultura dos novos habitantes, sobretudo da regiaao Sul do Brasil. Observamos, ainda, nos hábitos das pessoas, manifestaçōes do velho e do novo que conviviam concomitantemente. De um lado, pessoas locomovendo-se em jegues, uma característica da cultura camponesa do sertão, de outro, o estilo das sociedades ditas modernas, dentro do qual os automóveis importados e nacionais últimos modelos constituem os símbolos mais evidentes. Diante de tais observaçōes, sentimos a necessidade de entender a realidade que se colocava à nossa vista para além da aparência. Para tanto, precisariamos buscar um certo envolvimento com aquela sociedade, o qual estávamos iniciando naquele momento. ${ }^{7}$ Após contatos com camponeses, projeteiros ${ }^{8}$ e autoridades locais (que ocorreram tanto através de conversas 'descompromissadas' quanto de entrevistas sistematizadas, sendo que a maioria foi gravada), passamos a conhecer melhor o que realmente estava acontecendo com o processo de modernização daquela regiāo.

Após tal procedimento, chegamos a várias constatações, dentre elas, a de que a tão propalada modernização, veiculada pelos meios de comunicação (e pelo próprio Estado piauiense que procura, a todo custo, passar a idéia de que para sair do atraso econômico em que se encontra é preciso oferecer todas as facilidades para que o grande capital se interesse por aquele Estado), na prática, apresentava vários complicadores. Alguns deles originavam-se no próprio Estado, na medida em que este possuia um papel contraditório na condução daquele processo, pois ao mesmo tempo que anunciava a elaboração de politicas públicas direcionadas ao desenvolvimento dos cerrados, principalmente no Sul do Estado, estas nāo produziam efeitos práticos, ao menos no que se referia à infra-estrutura que dá sustentação à produção e aos setores de bem estar da população.

7 Obtive algumas facilidades nesse meu objetivo, pois temos parentes que residem em várias cidades da região.

8 Ma regiāo as pessoas que desenvolvem projetos agropecuários sāo chamadas de projeteiros 
Verificamos, por exemplo, que o sistema viário é totalmente deficitário, pois as estradas que "cortam" a regiāo estão praticamente intransitáveis, sendo que o mesmo ocorre com a energia elétrica, pois a falta de investimentos neste setor vem ocasionando quase que diariamente cortes em seu fornecimento, sobretudo para o Sul do Piauí. Em relação aos investimentos nos setores sociais, tais como educação e saúde, observamos que estes são praticamente nulos, o que aumenta ainda mais a carência daquela populaçāo.

Entretanto, em se tratando de estratégias para atrair o grande capital para as áreas de cerrados, o governo piauiense procura superar suas deficiências nos setores citados acima, concedendo grandes extensōes de terras, em sua maioria devolutas, aos 'investidores'. por preços praticamente irrisórios. Para se ter uma idéia, um hectare de terra na região pode ser comprado por R\$15,00. Este fato vem desencadeando um processo de concentração de terras ainda maior, em alguns casos, com o agravante de que muitos adquirem, através da compra, apenas uma parcela da terra, sendo que as outras são obtidas através da grilagem. ${ }^{9}$ É prática comum na regiāo, por exemplo, um 'investidor' comprar um parcela de terra e anexar, através do grilo, todas as outras que estão ao seu redor. Tal procedimento é facilitado pela pouca fiscalização que existe. O mais grave disso tudo é o fato de que os posseiros que viviam nessas terras, muitos há dezenas de anos, foram ou estão sendo expulsos, o que vem ocasionando, nos últimos anos, um aumento de famílias sem terras. Atualmente já são freqüentes os conflitos pela posse da terra em várias localidades da regiāo.

O trabalho de campo contribuiu ainda para desvendarmos outras questōes, as quais foram importantes para avançarmos em nossa pesquisa.

Um item apresentado, sobretudo pela imprensa, ${ }^{10}$ para identificar o sucesso da modernizaçāo, era o crescimento do número da população camponesa empregada com salário. Quando se tocava nesta questāo, freqüentemente aparecia a análise de que somente o fato da população local passar a ganhar um salário

9 Em reportagem sobre a grilagem na regiâo sul, o jornal piaviense "Diário do Povo" trazia, em 23 de agosto de 1996, a seguinte manchete: "Paraiso dos grileiros - o vice - governador Osmar Araújo aponta os municípios da regiào sul como os preferidos para a grilagem".

10 Existem poucos estudos mais aprofundados sobre o que vem acontecendo no sul do Piaui. Essa modernizaçāo é intepretada principalmente pela impresa ou por órgãos do governo do Estado que produzem alguns estudos nos quais procuram demonstrar a viabilidade econômica da regiào. mínimo já era um grande avanço, visto que os trabaIhadores que antes recebiam salários irrisórios quando conseguiam empregar sua mão-de-obra agora passariam a ter o privilégio de receber essa quantia. Procuramos, então, verificar de que forma essa melhora refletia-se na vida dos camponeses assalariados do local. Após conversas com os próprios camponeses e com alguns projeteiros, constatamos que os beneficiados com a modernização, quase sempre, resumemse a estes últimos, visto que, além de continuarem pagando salários irrisórios a seus empregados, estes somente sảo utilizados em determinados momentos de pico (no início da implantação do projeto ou em periodos de colheita) e para exercerem certas funçōes. No caso, as tarefas mais pesadas, como a de limpar a área, carregar sacos etc, sāo destinadas à população local, que na entressafra de suas atividades agrícolas complementa a renda familiar com o trabalho temporário. A mão-de-obra mais especializada é recrutada em outros lugares (normalmente em Barreiras/BA, onde a oferta de mão-de-obra que trabalha com maquinários é maior).

Diante dessa modernização perversa, ao camponès (aquele que ainda possui uma pequena propriedade) acaba restando como alternativa sua roça, de onde ele retira os meios de vida e, quando há excedentes de produtos, vende-os no mercado local. Encontramos vários camponeses nessa condição, que relataram a outra face dessa modernização, ou seja, aquela que exclui ainda mais a populaçāo pobre do local, a mesma que sempre ficou de fora de todos os recursos, que no discurso oficial e da academia, são destinados a resolver o problema da pobreza da regiāo; recursos que, no final das contas, acabam sendo desviados para a engorda do boi do pecuarista tradicional $e$ mais recentemente, também ao melhoramento da monocultura ou da pecuária do 'moderno' fazendeiro. A população camponesa, além de não ter acesso a nenhum desses recursos e aos equipamentos sociais básicos, tais como educação e saúde, ainda sofre com a desvalorização de sua condiçáo de camponês, na medida em que a modernizaçào passa a ser vista como um processo comandado pelos grandes agropecuaristas, que produzem essencialmente para o mercado.

Finalmente, um outro fenômeno que caracteriza aquele processo de modernização, o qual foi possivel desvendar somente com o trabalho de campo, refere-se ao fluxo migratório de população que ocorre na regiảo e que se manifesta através de duas correntes distintas e de sentidos contrários. 
Verificamos que uma dessas correntes é a representada por pessoas originárias do Sul e Sudeste do pais, e que vêm ocupando recentemente os cerrados piauienses. Constatamos, contudo, que a maioria dessa populaçāo não se desloca diretamen. te daquelas regiōes para o Piaui: muitos já participam de uma segunda migraçāo, pois sảo famílias que se instalaram inicialmente nas áreas das fronteiras agrícolas do Centro-Oeste (Mato Grosso, Mato Grosso do Sul e Goiás) e Nordeste (Oeste da Bahia) e agora deslocam-se para o Sul do Piaui em busca de terras baratas e incentivos fiscais do governo. Constatamos que nesse grupo existem duas categorias de migrantes. Uma categoria, representada por familias bem sucedidas, vai para o Piauí com capital para investir na compra de terras nos cerrados e utilizá-las para atividades agropecuárias. Neste caso, trata-se do avanço do capital sobre o cerrado piauiense. A outra é composta por famílias descapitalizadas, que, comumente, venderam suas propriedades nas 'antigas' fronteiras, principalmente pelas dificuldades em mantê-las produzindo ou mesmo pela valorização das terras naquelas regiōes, e vão tentar a sorte no Plauí. Segundo o que me relataram alguns dos migrantes dessa última categoria, ocorria que compensava mais vender seus antigos lotes, mesmo que pequenos, e investir o dinheiro obtido nas terras do Piaui, pois estas possuiam pre. ços bem menores em relação aos de outros lugares. Porém, apesar de uma parcela dessas familias com pouco capital ter conseguido comprar terras na regiāo, as dificuldades encontradas, sobretudo para torná-las produtivas (falta de condiçōes básicas de infra-estrutura, dificil acesso às propriedades etc) fez com que muitas abandonassem o projeto inicial, algumas delas preferindo até mesmo fazer o caminho de volta, principalmente aquelas que ainda mantinham vinculos familiares com a regiāo de origem. Uma outra parcela desses migrantes optou por permanecer nas cidades da própria regiāo, mas dedicando-se às atividades comerciais. Os que insistem em permanecer em suas propriedades vivem a mesma condição dos camponeses piauienses.

A outra corrente migratória é a de piauienses que se deslocam para os grandes centros urbanos (principalmente São Paulo e Brasília). Saem em busca de melhores condiçōes de vida, já que a modernizaçāo em curso na regiảo não consegue beneficiálos. Resta então a essa população camponesa, uma única opção: migrar. Entre esses migrantes, observamos que existe uma parcela significativa de famili- as que possuem pequenos lotes de terras, mas que dificilmente se desfazem delas quando migram (normalmente migram apenas alguns membros da familia, às vezes, o chefe, outras vezes, os filhos mais velhos), e sim comumente partem com o intuito de permanecerem donos da terra.

Nesse sentido, foi possivel perceber que a terra é um elemento central para os vários segmentos que ali chegaram ou que ali sempre viveram. Para o investidor capitalista, por exemplo, representa uma fonte de lucro, seja através da agropecuária comercial ou simplesmente da especulação. Para os camponeses piauienses ou os migrantes 'sulistas' pobres (aqueles que conseguiram terras e permanecem nelas) representa uma fonte de sobrevivência.

Diante das questões aqui apresentadas, concluimos que o trabalho de campo constitui uma ferramenta extremamente útil para o nosso trabalho de pesquisa. Ele representa uma oportunidade de compreender melhor determinadas manifestações da realidade, as quais, na maioria das vezes, somente com trabalho de gabinete não conseguiriamos nem ao menos perceber.

A meu ver, a observação de uma dada paisagem possui, dentre outras dimensóes, a riqueza de colocar em contato direto o investigador com o objeto investigado. Contudo, esse procedimento exige que tal investigador possua muita sensibilidade e ao mesmo tempo preparo para lidar também com determinadas situações, às vezes adversas, para interpretar uma realidade que se manifesta como múltiplos fatores e processos, muitos dos quais pouco perceptiveis à primeira vista. Messe sentido, é preciso que o investigador tenha o minimo de vivência com a realidade que pretende estudar, e que adquira a confiança das pessoas com quem pretende obter informaçōes; somente a partir de então, torna-se mais fácil desvendar tais manifestaçōes.

Nessa nossa experiência de trabalho de campo, defrontamo-nos com algumas das situaçōes colocadas acima, uma delas, por exemplo, foi a da desconfiança inicial das pessoas em relação aos motivos pelos quais éramos levados a querer informaçōes sobre suas vidas. Contudo, essa desconfiança foi cedendo lugar à empatia e à credibilidade do pesquisador, pois, com o passar do tempo, eles próprios descobriram na nossa relaçāo que tínhamos raizes nos lugares a admitiram que já éramos 'velhos conhecidos' Este fato facilitou uma maior aproximação, sobretudo com os camponeses piauienses. Com a abertura que nos deram, pudemos realizar certo 
acompanhamento do cotidiano da vida daquelas pessoas, o que nos permitiu obter uma outra visão da modernização. Esta é vista, agora, pelo olhar dos camponeses, resgatando outras dimensōes de suas vidas, dando-lhes transparência e fazendo-os emer- gir do discurso hegemônico e homogenizador (oficial ou acadèmico) como sujeitos sociais que concebem, produzem e representam o 'seu' espaço, hoje em transformaçāo.

\section{BIBLIOGRAFIA}

COSTA, R. Haesbaert da. "Gaúchos" no Nordeste: Modernidade, Des-Territorialização e Identidade. Tese de Doutorado. São Paulo, FFLCH/USP, 1995.

DIÁRIO DO POVO. Teresina, 07 de maio de 1996.

DIÁRIO DO POVO. Teresina, 23 de agosto de 1996.

FOLHA DE SĀO PAULO. Caderno Agrofolha. São Paulo, 23 de outubro de 1996, p.3.

GOVERNO DO PIAUIí. Processo de Planejamento estratégico do Estado do Piauí. Teresina, 1995.

HUMBOLDT, Alexandre von. Cosmos. Paris, Gide Et J. Baudry, 1848.

MEIO NORTE. Teresina de 1996.

MORAES, Antônio Carlos R. Contribuição para uma História Crítica do Pensamento Geográfico: Alexandre von
Humboldt, Karl Ritter e Friedrich Ratzel. Tese de Doutorado. São Paulo, FFLCH-USP,1983.

O DIA. Teresina, 01 de agosto de 1996.

O DIA. Teresina, 28 de setembro de 1995.

RIBEIRO, Efrém. O Piaui que Dá Certo. In: Revista ISTO É, Agosto de 1994, n(1296.

TORRES, R.W.C.. "Cerrados Piauienses: O Celeiro de Alimentos em Exploração". In: Carta CEPRO. Teresina, V.15, n(01), jan/jun, 1994.

TORRES, R.W.C. \& COSTA, M.E. "Os Cerrados do Piauí e seus Aspectos Sócio-Econômicos" In: Carta CEPRO. Teresina, V.14, n(1), jul/dez,1995.

VALVERDE, Orlando. Geografia Agrária do Brasil. Rio de Janeiro, CBPE/INEP/MEC,1964. 